\title{
Influence of Dipole Interactions on Mechanical Behavior of Modified E poxy Resins
}

\author{
Weidong ZhaNG, Wenqi Lu, Shengguo WANG, and Hongwei ZHOU ${ }^{\dagger}$ \\ Department of Macromolecular Science, Fudan University, No. 220 Handan Road, Shanghai, \\ 200433, the People's Republic of China
}

(Received November 7, 2002; Accepted March 23, 2003)

\begin{abstract}
In this article, Influence of dipole interactions on tensile properties, fracture toughness and glass transition of epoxy resins was investigated by comparing the poly ethylene glycol (PEG) and carboxyl-terminated butadiene acrylonitrile (CTBN) modified epoxy systems. The infrared spectroscopy (IR) spectrums proved that there existed polar interactions between epoxy network and PEG chain. The results showed that dipole interactions played a significant role in influencing on toughness and strength of epoxy resins but had little effect on their glass transition temperature.

KEY WORDS Epoxy Resins / Dipole Interactions / Toughening /
\end{abstract}

Epoxy resins are widely used in coating, adhesive, insulating, flooring, laminating, casting, and structural applications because of their excellent physical and chemical properties that result from their highly crosslinked network structure. However, one major drawback of epoxy resins is their poor resistance to impact and crack initiation. Consequently, enormous efforts have been made to improve their fracture toughness while still maintaining their desirable properties. ${ }^{1,2}$

The fracture toughness of epoxy resins can be improved by the introduction of diluents, flexblizers, reactive liquid rubbers, thermoplastics, and liquid crystal polymers et al. ${ }^{3-5}$ Many toughening mechanisms have been proposed and accepted based on these studies. On the other hand, secondary-bond forces on miscibility and toughening behavior of modified epoxy resins are relatively less understood.

Guo et al. ${ }^{6,7}$ studied PEG modified epoxy systems and they concluded that the hydrogen-bonding interaction was considered to be one of the main driving force for the miscibility in the thermoplastic-thermosetting polymer blends.

Zhao et al. ${ }^{8}$ studied amine cured epoxy systems modified by carboxyl-terminated propylene ether (CTPE) with low molecular weight $\left(M_{\mathrm{n}}=700\right)$. When the content of CTPE increased from $10 \%$ to $20 \%$, its fracture energy $G_{\mathrm{IC}}$ decreased from $158 \mathrm{~kJ} \mathrm{~mol}^{-1}$ to $131 \mathrm{~kJ} \mathrm{~mol}^{-1}$ and impact strength decreased from $1637 \mathrm{~J} \mathrm{~m}^{-2}$ to $1313 \mathrm{~J} \mathrm{~m}^{-2}$. However, when the molecular weight of CTPE increased to more than 1300, phase separation occurred in the modified epoxy systems and hydrogen-bonding interactions were weakened. The fracture energy $G_{\mathrm{IC}}$ and impact strength of modified epoxy systems increased with the content of CTPE within the range from $0-20 \%$. Their study showed that hydrogen-bonding interactions between toughening agents and epoxy network would influence the mechanical properties of epoxy resins drastically.

Guo et $a l .{ }^{6}$ studied the phenoxy/diglycidyl ether of bisphenol A (DGEBA) system cured with a series of different hardeners. Lieberman ${ }^{9}$ investigated the miscibility of poly (ethylene oxide) (PEO) and poly (methyl methacrylate) (PMMA). They concluded that the hydrogen bonding itself did not seem to be sufficient to guarantee an intimate and strong interaction leading to phase homogeneity, but polar interactions between these two components were likely, and believed to be responsible for the noted miscibility.

However, there are few studies on other secondarybond forces influencing on toughening behavior of modified epoxy resins. In this paper, we used poly ethylene glycol (PEG) and carboxyl-terminated butadiene acrylonitrile (CTBN) to modify DGEBA/methyl hexahydrophalic anhydride (MeHHPA)/benzyl dimethylamine (BDMA) epoxy systems, in these systems, hydrogen bonding is not significant, the main interaction was electrostatic force (dipole interactions), ${ }^{9,10}$ and we studied influence of dipole interactions on tensile properties, impact strength, fracture toughness $\left(G_{\mathrm{IC}}\right)$, glass transition temperature, and crack resistance test of epoxy resins under thermal shock.

\section{EXPERIMENTAL}

\section{Materials}

The epoxy system used in this study is a diglycidyl ether of bisphenol A (DGEBA) epoxy resin (DER331) cured with methyl hexahydrophalic anhydride (MeHHPA) and catalyzed by a tertiary amine benzyl dimethylamine (BDMA). DER331 was purchased

${ }^{\dagger}$ To whom correspondence should be addressed (Tel: +86-2165647981, E-mail: wdz7712@hotmail.com). 
from Dow Chemical Company, MeHHPA from Lonza Company and BDMA from Shanghai Third Agent Factory. The toughening agents are PEG $\left(M_{\mathrm{n}}=400\right)$ and CTBN $\left(M_{\mathrm{n}}=2200\right)$. PEG was purchased from Shanghai Pudong Gaonan Chemical Factory, and CTBN from Institute of Chemical Engineering, Lanzhou Chemical Industrial Company. The composition of epoxy systems in weight is as follows: epoxy $100 \mathrm{phr}$, MeHHPA $88 \mathrm{phr}$ and BDMA $0.14 \mathrm{phr}$. The toughening agents are $1 \mathrm{phr}, 5 \mathrm{phr}, 10 \mathrm{phr}, 15 \mathrm{phr}, 20 \mathrm{phr}, 25 \mathrm{phr}$, and $30 \mathrm{phr}$, respectively.

\section{Sample Preparation}

Epoxy resin DER331, curing agent MeHHPA, catalyst BDMA, and toughening agents are mixed together and stirred for about $5 \mathrm{~min}$ to uniformity and then put into an vacuum oven for degassing. After that we cast the epoxy resin compounds into molds coated with silicone mold release agent, then put these molds into the oven for curing. The curing procedure is as follows: $90^{\circ} \mathrm{C} / 3 \mathrm{~h}, 110^{\circ} \mathrm{C} / 2 \mathrm{~h}, 130{ }^{\circ} \mathrm{C} / 1 \mathrm{~h}$, and $140{ }^{\circ} \mathrm{C} / 12 \mathrm{~h}$.

\section{Measurement}

Tensile Properties. Tensile strength and modulus of epoxy resins are tested on Instron1121 according to GB2568-81. When testing tensile strength, the crosshead displacement speed was $10 \mathrm{~mm} \mathrm{~min}^{-1}$; while testing tensile modulus, the crosshead displacement speed was $1 \mathrm{~mm} \mathrm{~min}^{-1}$. Five samples were tested for each case.

Impact Strength, Fracture Toughness, and Crack Resistance Test. Charpy impact strength of epoxy systems was tested according to GB1043-79 and performed on XCJ-40 impact tester. The dimension of test specimen was $120 \times 15 \times 10 \mathrm{~mm}^{3}$ and 10 specimens were tested for each case.

The critical strain energy release rate $G_{\mathrm{IC}}$ was determined on Instron 1121 according to the literature. ${ }^{11}$ Five specimens $\left(75 \times 42 \times 3 \mathrm{~mm}^{3}\right)$ were tested for each case.

Crack resistance test of epoxy resins under thermal shock was determined according to the literature. ${ }^{12}$

Glass Transition Temperature and Fourier Transform Infrared (FT-IR) Spectroscopy. A Netzsch DMA242 was used to measure the glass transition temperature of epoxy systems. The double cantilever mode operating at $10 \mathrm{~Hz}$ and a heating rate of $3 \mathrm{~K} \mathrm{~min}^{-1}$ from $25^{\circ} \mathrm{C}$ to $200^{\circ} \mathrm{C}$. The specimen dimensions were $42 \times 10 \times 3 \mathrm{~mm}^{3}$. The glass transition temperature was defined as the temperature corresponding to the maximum value of loss factor.

FT-IR spectroscopy has been used to prove polar interactions between epoxy network and PEG molecular chain. For the IR measurements, a small portion of the cured epoxy system was ground to a fine powder, mixed with potassium bromide $(\mathrm{KBr})$ powder and pressed into a pellet. FT-IR spectra were recorded on a Nicolet Nexus 470 FT-IR spectrometer.

\section{RESULTS AND DISCUSSIONS}

\section{FT-IR Spectroscopy}

A series of IR spectrum for neat epoxy and $5 \mathrm{phr}$, $10 \mathrm{phr}$, and $30 \mathrm{phr}$ PEG modified epoxy resins have been obtained to reveal the presence or absence of any polar interactions between epoxy network and the molecular chain of PEG. They are presented in Figure 1. Figure 1a illustrates the IR absorption spectrum of the pure epoxy, $5 \mathrm{phr}, 10 \mathrm{phr}$, and $30 \mathrm{phr}$ PEG modified epoxy resins. In Figure $1 \mathrm{~b}$ the absorption peaks between 1735 and $1740 \mathrm{~cm}^{-1}$ are due to the stretching vibrations of $\mathrm{C}=\mathrm{O}$ bond in ester group of epoxy network. In Figure 1c the absorption peaks between 1240 and $1250 \mathrm{~cm}^{-1}$ are due to the stretching vibration of $\mathrm{C}-\mathrm{O}$ bond neighboring to $\mathrm{C}=\mathrm{O}$ in ester group. The wave number of $\mathrm{C}=\mathrm{O}$ bond absorption peaks of $0 \mathrm{phr}, 5 \mathrm{phr}, 10 \mathrm{phr}$, and $30 \mathrm{phr}$ PEG modified epoxy resins are $1739.5 \mathrm{~cm}^{-1}, 1736.0 \mathrm{~cm}^{-1}, 1735.9 \mathrm{~cm}^{-1}$, and $1735.7 \mathrm{~cm}^{-1}$ respectively. The wave number of corresponding $\mathrm{C}-\mathrm{O}$ bonds are $1238.8 \mathrm{~cm}^{-1}, 1240.5 \mathrm{~cm}^{-1}$, $1246.8 \mathrm{~cm}^{-1}$, and $1248.6 \mathrm{~cm}^{-1}$. Obviously, the wavenumber shift of $\mathrm{C}-\mathrm{O}$ bond absorption peaks is greater than that of $\mathrm{C}=\mathrm{O}$ bond absorption peaks. The change of wave number may be due to the interaction between PEG and epoxy network.

According to the literature, ${ }^{13}$ dipole interaction existed between PEG chain and ester group in epoxy network, as shown in Figure 2. This interaction makes the electron cloud density in $\mathrm{C}=\mathrm{O}$ bond of ester group decrease and the electron cloud density in $\mathrm{C}-\mathrm{O}$ bond of ester group increase, thus makes carbonyl group absorption peak shift to low wave number direction and the vibrating frequency of $\mathrm{C}-\mathrm{O}$ bond shift to high wave number. The stronger the polar interactions, the more the wave number shifts.

The FT-IR spectrums indicate that obvious dipole interactions exist between epoxy network and backbone of PEG.

\section{Influence of PEG and CTBN on Mechanical Properties}

The mechanical properties of modified epoxy resins were listed in Table I and Table II. From the two tables, we could easily see that initially the tensile strength increased with the adding of PEG and CTBN then decreased with their more content, the fracture energy of modified epoxy resins increased with content of CTBN and PEG. It's very obvious that with the same con- 

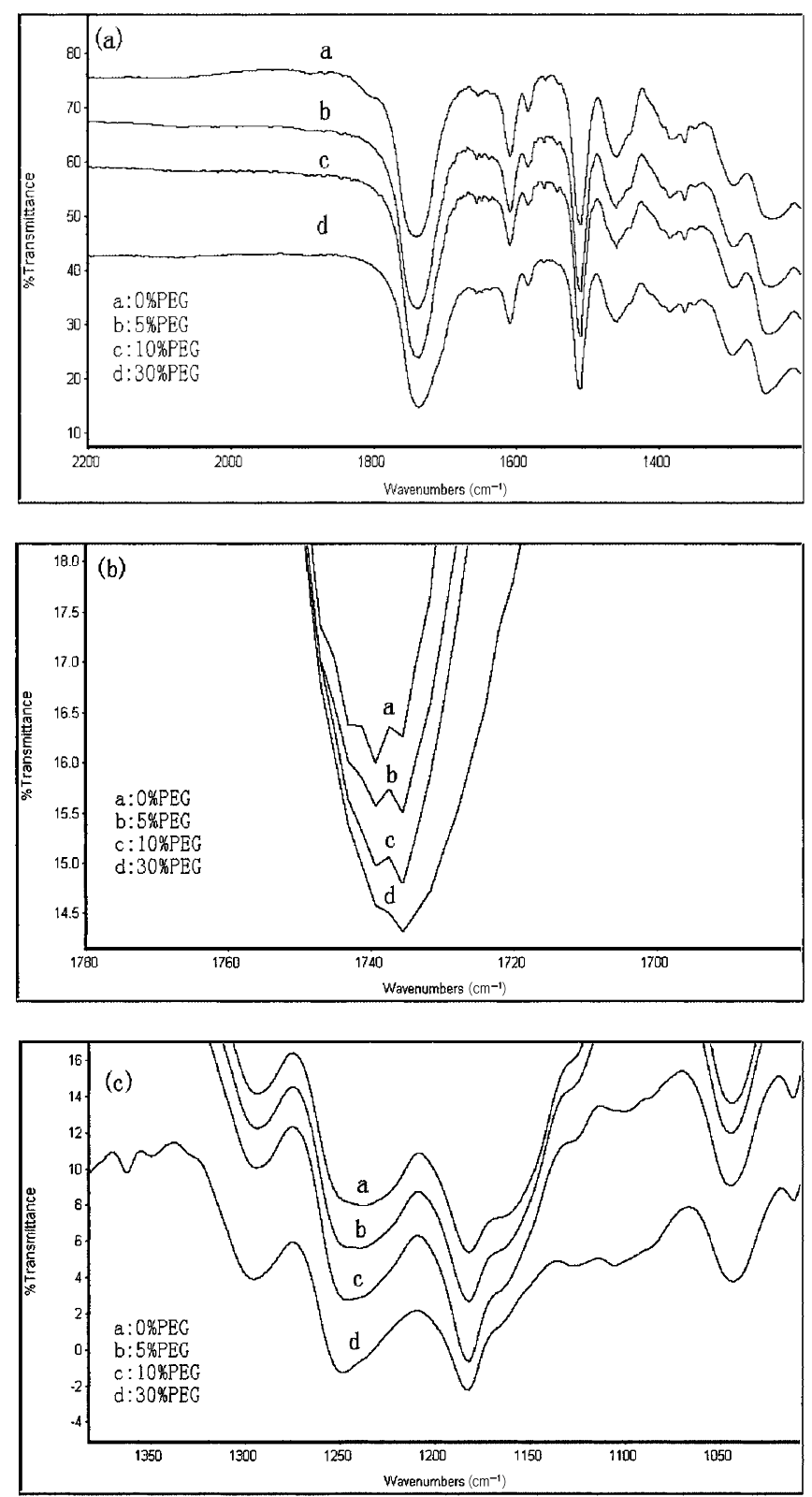

Figure 1. (a) FT-IR absorption spectrum of epoxy resins. (b) FT-IR absorption spectrum of $\mathrm{C}=\mathrm{O}$ bonds in ester group of epoxy resins. (c) FT-IR absorption spectrum of $\mathrm{C}-\mathrm{O}$ bonds in ester group of epoxy resins.

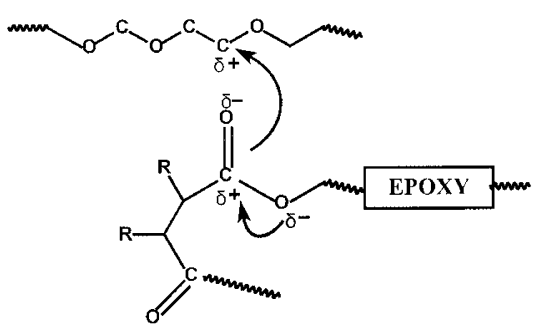

Figure 2. Scheme of polar interactions between carbonyl and ether groups.

tent, the tensile strength, tensile modulus, and impact strength of PEG modified epoxy resin were higher than those of CTBN modified ones.

It should note that initially the tensile modulus of PEG modified epoxy resins decreased with the adding of PEG then increased with the increasing of their content, but the glass transition temperature decreased drastically with their content, different from that of CTBN modified epoxy resins. And with the same amount, the glass transition temperature of PEG modified epoxy system is lower than that of CTBN modified system, but its modulus is obviously higher than the CTBN modified system, as shown in Figures $3 a$ and $3 b$.

In recent years, it has become increasing recognized that for epoxy thermosets the relationship between the glass transition temperature and modulus often runs count to that generally reported for thermoplastic polymer. ${ }^{14}$ Specifically, the modulus of a wide variety of epoxy resin systems has been seen to increase as their 
Table I. Mechanical properties of CTBN modified epoxy resins

\begin{tabular}{lrrrrrrrr}
\hline & & $0 \%$ & $1 \%$ & $5 \%$ & $10 \%$ & $15 \%$ & $20 \%$ & $30 \%$ \\
\hline Tensile strength & $(\mathrm{MPa})$ & 61.3 & 81.3 & 76.2 & 73.3 & 70.3 & 64.1 & 54.9 \\
Tensile modulus & $\left(10^{3} \mathrm{MPa}\right)$ & 2.50 & 2.42 & 2.08 & 1.97 & 1.89 & 1.90 & 1.52 \\
Impact strength & $\left(\mathrm{KJ} \mathrm{m}^{-2}\right)$ & 13.2 & 13.6 & 16.0 & 15.6 & 15.2 & 13.1 & 17.9 \\
$G_{\text {IC }}$ & $\left(\mathrm{KJ} \mathrm{m}^{-2}\right)$ & 351.0 & 442.7 & 670.4 & 917.1 & 1274.4 & 1527.3 & 2126.4 \\
\hline
\end{tabular}

Table II. Mechanical properties of PEG modified epoxy resins

\begin{tabular}{lcccccccc}
\hline & & $0 \%$ & $5 \%$ & $10 \%$ & $15 \%$ & $20 \%$ & $25 \%$ & $30 \%$ \\
\hline Tensile strength & $(\mathrm{MPa})$ & 61.3 & 83.8 & 80.4 & 77.2 & 74.5 & 68.7 & 54.8 \\
Tensile modulus & $\left(10^{3} \mathrm{MPa}\right)$ & 2.50 & 2.03 & 2.31 & 2.44 & 2.36 & 2.58 & 2.49 \\
Impact strength & $\left(\mathrm{KJ} \mathrm{m}^{-2}\right)$ & 13.2 & 18.6 & 19.9 & 20.0 & 21.7 & 19.0 & 20.2 \\
$G_{\text {IC }}$ & $\left(\mathrm{KJ} \mathrm{m}^{-2}\right)$ & 351.0 & 496.1 & 695.2 & 837.4 & 1592.6 & 4379.8 & 6797.2 \\
\hline
\end{tabular}
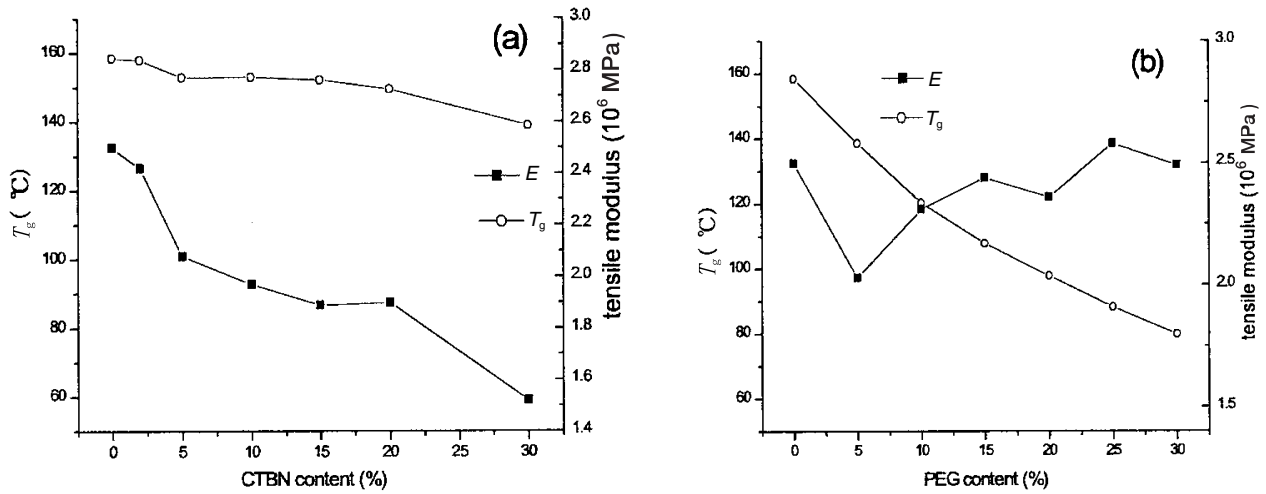

Figure 3. Tensile modulus and glass transition temperature of CTBN modified epoxy $v$ s. content of CTBN. (b) Tensile modulus and glass transition temperature of PEG modified epoxy vs. content of PEG.

$T_{\mathrm{g}}$ 's decrease. This behavior has been studied in detail by Gillham and students. ${ }^{15-17}$ Gillham et al. found that in not fully cured epoxy diaminodiphenylsulfone (DDS) systems the modulus decreased as their glass transition temperature increased. It is contributed to that the density decreases with increasing glass transition temperature because the increase in unoccupied volume that is frozen into glass by virtue of higher glass transition temperature, is greater than the decrease in unoccupied volume that is caused by polymerization shrinkage at the temperature. It has been also found modulus increasing in other toughened epoxy systems, which may be due to the inherent high modulus of added plastics. ${ }^{18}$

Our epoxy systems are different from those of Gillham. In our systems, the epoxy resins are fully cured and the PEG chain with high flexibility and low modulus incorporates into epoxy network. There are many ether groups in PEG modified epoxy systems, which makes the non-chemical bonding such as dipole interactions induce easily, as illustrated in Figure 1. Consequently, we contribute the increasing of modulus to the non-chemical interaction between chains in the epoxy network.

In PEG modified systems, there are two important factors that have contrary influence on the nature of the epoxy networks. The first one is PEG chain incorporating into the network of epoxy resin, which decreases the cross-linking density of the network and increases the mobility of network. The second one is the dipole interactions between PEG chain and the epoxy network. These interactions acted as physical crosslinking sites, thus decrease the mobility of network chain. The intensities of the two factors increase with the increasing of the content of PEG. Regarding the tensile modulus of PEG modified epoxy systems the influence of dipole interactions on them is greater than the influence of the PEG chains' flexibility on them within a certain range.

According to literature, ${ }^{19}$ the dipole interactions between molecules can be expressed as in eq 1 .

$$
U=-\frac{2}{3}\left(\frac{\mu_{1} \mu_{2}}{r^{6}}\right) \frac{1}{\kappa T}
$$

In the equation, $U$ is the interaction between two polar molecules; $\mu_{1}$ and $\mu_{2}$ are dipole moments of two polar molecules, $r$ is the distance between the center of gravity of the two molecules, $\kappa$ is the Boltzmann constant and $T$ is the absolute temperature.

From eq 1, we can see that the intensity of dipole interaction decreases with the increasing of temperature. At the glass transition temperature of epoxy, the dipole 


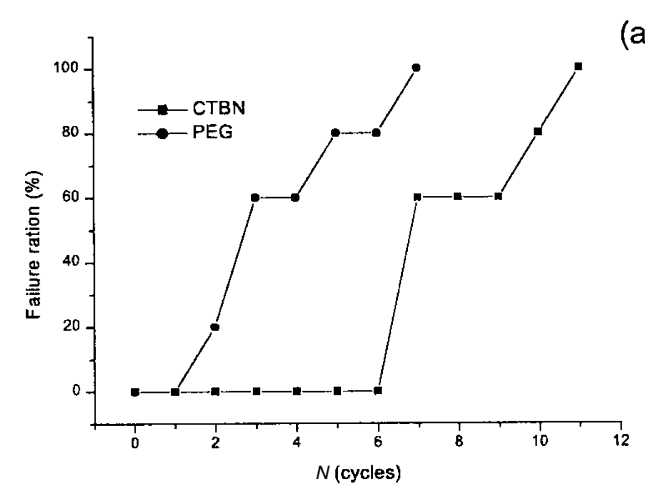

(a)

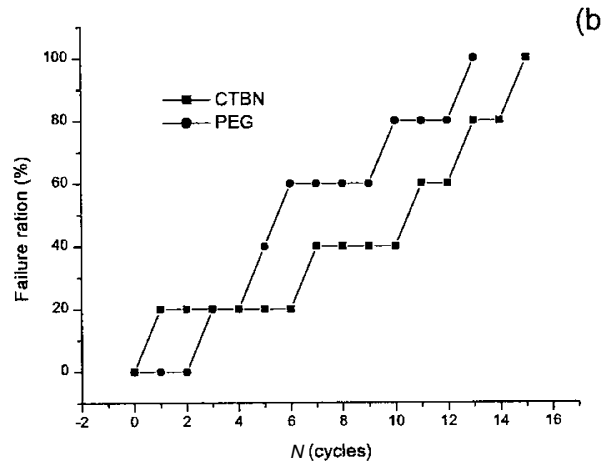

(b)

Figure 4. Crack resistance of epoxy resins under thermal shock (a) $20 \%$ CTBN and $20 \%$ PEG modified epoxy resins, (b) $30 \%$ CTBN and $30 \%$ PEG modified epoxy resins.

interactions become weaker, thus the dipole interaction has little effect on the glass transition temperature of epoxy resin. The flexible chain of PEG that incorporated into epoxy network plays a dominated role in the glass transition of epoxy resin. For CTBN modified system, the chain of CTBN is partly incorporated into the epoxy network. As a result, the glass transition temperature of PEG modified system is obviously lower than the CTBN modified system with the same added amount.

The result shows that the unusual relationship between the modulus and glass transition temperature of PEG modified system originates from the dependence of dipole interaction on the temperature.

Similar studies have been reported in other literatures. Regarding the frequently studied CTPE and carboxyl terminated tetrahydrofuran-propylene ether copolymer (CTCPE), ${ }^{20}$ although their structure and polarity is similar to that of PEG, there is one side $-\mathrm{CH}_{3}$ group in their repeating unit, which makes the steric hindrance increase and weakens the dipole interaction. So their modulus decreased with the increasing of added amount, different from PEG.

\section{Influence of Dipole Interactions on Crack Resistance under Thermal Shock}

We also conducted crack resistance test of epoxy resins under thermal shock. A thermal shock test cycle includes $-18^{\circ} \mathrm{C}$ for $3 \mathrm{~h}$ and $50^{\circ} \mathrm{C}$ for $2 \mathrm{~h}$. The number of specimens for each epoxy compound is 5 , if a specimen cracks the failure ratio of crack is $20 \%$, and so on. Thermal shock testing continues until all the specimens crack. $N$ in Figure 4 stands for the number of thermal shock testing cycles. We found an interesting fact, illustrated in Figure 4. From the two tables we could find when the content was $20 \mathrm{phr}$ and $30 \mathrm{phr}$, the fracture toughness and impact strength of PEG modified epoxy resins were better than those of corresponding CTBN modified epoxy resins, while their crack resis- tance under thermal shock is much lower than those of CTBN modified epoxy resins. According to some literatures $^{21,22}$ and our past study, ${ }^{12}$ usually the crack resistance under thermal shock of epoxy resins with higher toughness is better than that of epoxy resins with lower toughness.

Since all specimens crack at $-18^{\circ} \mathrm{C}$, we contribute the unusual relationship between fracture toughness at ambient temperature and crack resistance of PEG modified epoxy under thermal shock to the intensifying of dipole interaction, which is influenced by temperature. According to eq 1 , we can see that with the temperature decreasing, the dipole-dipole interactions between polar molecules increase and will decrease the chain mobility drastically at low temperature. Although the flexible PEG chain increases the network's mobility, the influence of dipole interactions is greater at low temperature, thus decrease its crack resistance under thermal shock. Regarding the relatively low polar CTBN modified systems, because the dipole interaction is very weak, the influence of temperature on toughness at low temperature is not so significant as that of PEG.

\section{CONCLUSIONS}

In this article, influence of dipole interactions on tensile properties, fracture toughness and glass transition of epoxy resins is investigated by comparing PEG and CTBN modified epoxy systems.

In some systems, such as PEG modified epoxy systems, there exist strong dipole interactions, which can obviously increase the tensile strength and modulus of the modified epoxy systems with the increasing of PEG content, although the incorporated PEG chains have excellent flexibility. The dipole interactions act as physical cross-linking sites, thus decrease the mobility of network chain and partially counteract the effect of flexible PEG chain incorporated in the network. Since the intensity of dipole interactions decreases with the 
increasing of temperature, the influence of dipole interactions on the glass transition of epoxy systems is not obvious.

The influence of temperature on the toughness is greater in epoxy systems with strong dipole interactions than that in epoxy systems with weak dipole interaction, because intensity of dipole interaction increases with the decreasing of temperature. As a result, such system with excellent toughness at room temperature has poor crack resistance under thermal shock; in other words, its toughness at low temperature is poor.

Our results can be used to select appropriate toughening agents. When selecting toughening agents, we need not take polarity of toughening agents into account at room or higher temperatures. However, the polarity of toughening agents must be taken into account at low temperature; in this case, we should select toughening agents with low polarity.

\section{REFERENCES}

1. T. Iijima, A. Sugizaki, W. Fukuda, and M. Tomoi, Polym. Int., 44, 125 (1997).

2. D. R. Paul and C. B. Bucknall, Ed., "Polymer Blends: Performance”, John Wiley \& Sons, Inc., New York, N.Y., 1999, vol. 2, chapt. 26.

3. V. D. Liello, E. Martuscelli, R. Muso, G. Ragosta, and G. Scarrinzi, J. Polym. Sci., Phys. Ed., 32, 409 (1994).

4. N. Chikhi, S. Fellahi, and M. Bakar, Eur. Polym. J., 38, 251
(2002).

5. R. A. Pearson and A. F. Yee, Polymer, 34, 3658 (1993).

6. Q. Guo, Polymer, 36, 4753 (1995).

7. Q. P. Guo, X. S. Peng, and Z. J. Wang, Polymer, 32, 53 (1991).

8. S. Zhao, X. Jiang, X. Zhang, and Y. S. Sun, Thermosetting Resins(Chinese), 2, 1 (1987).

9. S. A. Liberman and A. D. S. Gomes, J. Polym. Sci., Polym. Chem. Ed., 22, 2809 (1984).

10. X. Li, J. Polym. Sci., Polym. Chem., 22, 133 (1984).

11. A. Christiansena and J. B. Shortall, J. Mater. Sci., 11, 1113 (1976).

12. S. Wang, Q. Li, W. Zhang, and H. Zhou, Polymer Testing, 21, 194 (2002).

13. T. J. Horng and E. M. Woo, Polymer, 39, 4115 (1998).

14. C. B. Arends and D. E. Hudgin, Ed., "Polymer Toughening", Marcel Dekker, Inc., New York, N.Y., 1996, chapt. 10.

15. J. B. Enns and J. K. Gillham, J. Appl. Polym. Sci., 28, 2831 (1983).

16. K. Pang and J. K. Gillham, J. Appl. Polym. Sci., 37, 1969 (1989).

17. X. Wang and J. K. Gillham, J. Coat. Technol., 64, 37 (1992).

18. G. S. Bennett, R. J. Farris, and S. A. Thompson, Polymer, 32, 1633 (1991).

19. H. Zhao, J. Jiang, D. Wu, and M. Tan, "Polymer Physics", Textile Industrial Publication, Beijing, 1982.

20. X. Tian, J. Ju, and Z. Dai, Thermosetting Resins, 4, 6 (1988).

21. Y. Kojima, T. Ohta, M. Matsushita, M. Takahashi, and T. Horauchi, J. Appl. Polym. Sci., 41, 2199 (1990).

22. M. Shimbo, M. Ochi, T. Inamura, and M. Inoue, J. Mater. Sci., 20, 2965 (1985). 